\title{
EDITORIAL
}

\section{Take turmeric with a grain of salt}

\author{
Kirsten Patrick MB BCh, Matthew B. Stanbrook MD PhD
}

Cite as: CMAJ 2018 October 29;190:E1270. doi: 10.1503/cmaj.181358

See related article at www.cmaj.ca/lookup/doi/10.1503/cmaj.180510

$\mathbf{P}$ erhaps you've heard that turmeric, the golden curry spice, is the new wonder supplement. Turmeric contains curcumin, which Google - without my needing to click through to any website - tells me can help prevent heart disease, Alzheimer disease and cancer, as well as relieve symptoms of depression and arthritis. Curcumin has exciting, powerful anti-inflammatory properties, apparently. And this wonder supplement of the age has been marketed so well that we can now buy turmeric lattes in ordinary chain coffee shops and turmeric smoothies just about everywhere. There is some evidence to support curcumin's anti-inflammatory effects, which is why the authors of a linked research study sought to examine its effectiveness in preventing organ damage following major vascular surgery. ${ }^{1}$ Unsurprisingly, the findings of this large multicentre randomized controlled trial don't support the widespread claims of powerful anti-inflammatory properties of curcumin, highlighting the importance of studying natural health products like this.

Garg and colleagues randomized more than 600 patients, scheduled for elective abdominal aortic aneurysm repair at 1 of 10 Canadian hospitals, to either high-dose perioperative oral curcumin or placebo. They looked at levels of four biomarkers of tissue inflammation in the hours and days after surgery. At a dose of $2000 \mathrm{mg}$ twice a day over four days - a dose much higher than usual dietary consumption - oral curcumin was no more effective than placebo in ameliorating the inflammatory complications of aortic aneurysm repair. Examination of secondary outcomes showed a higher risk of postoperative kidney injury in the curcumin supplementation group, but no differences in adverse-effect profiles. ${ }^{1}$

The authors carried out this study because a small single-centre randomized trial of patients scheduled for elective coronary artery bypass grafting found a reduction in three inflammatory biomarkers among those who took oral curcumin perioperatively, ${ }^{2}$ and animal studies had indicated an effect before that. They did the right thing. Building on promising pre-clinical and preliminary work by undertaking a larger and more rigorous trial is what pharmaceutical companies do all the time when testing new drugs. The dumpsters of these companies are filled with compounds that should have worked (based on preclinical work), but then sadly weren't found to be effective in large-scale human trials. No one should be shocked by the findings of the study by Garg and colleagues. This is how science works. It's deeply disappointing when a promising compound is shown to be no better than nothing. But it happens every day.

Except it doesn't happen every day for natural health products touted as having wondrous medicinal properties. Health Canada does not hold "natural" health products to the same high standard as it does pharmaceutical products. As CMAJ editors have previously pointed out, manufacturers of natural health products can sell a product and claim health benefits without having to obtain the same supporting evidence that would be needed if it were sold as a drug. ${ }^{3,4}$ With natural health products, the marketing most often comes first - usually based on few small, nonrandomized and unblinded studies at best - and the good science usually fails to follow. "But it's natural; it can't cause harm," shout the purveyors of natural health products. Yet natural doesn't mean safe or even good. Caffeine is natural. Many people enjoy its effects and may find them to enhance well-being, but excess consumption can harm. Tobacco is natural. So is arsenic.

We need lots more studies like the linked trial by Garg and colleagues. We need to know when a substance that offers much hope and, through poor regulation, benefits from premature hype is actually useless or harmful. Although not every natural health product may be studied, priority-setting for research may include its breadth of use and likelihood of benefit or harm.

Consumers may still prefer a turmeric to a pumpkin spice latte, but at least they will now be able to hand over their money knowing that a proven health benefit is lacking. Natural health products should be subject to a high standard of scientific testing, journals should publish and promote these high-quality studies for the public good, and purveyors of natural health products need to be as willing - or should be regulated to be as willing - to admit that their health claims are wrong when good science demonstrates them to be so.

\section{References}

1. Garg AX, Devereaux PJ, Hill A, et al.; Curcumin AAA AKI Investigators. Oral curcumin in elective abdominal aortic aneurysm repair: a multicentre randomized controlled trial. CMAJ 2018;190:E1273-80.

2. Wongcharoen W, Jai-Aue S, Phrommintikul A, et al. Effects of curcuminoids on frequency of acute myocardial infarction after coronary artery bypass grafting. Am J Cardiol 2012;110:40-4.

3. Stanbrook MB. Natural health products should be sold separately from drugs CMAJ 2017;189:E848.

4. MacDonald NE, MacLeod S, Stanbrook MB, et al. No regulatory double standard for natural health products. CMAJ 2011;183:2079.

Competing interests: See www.cmaj.ca/site/misc/cmaj_staff.xhtml

Affiliations: Deputy editor, CMAJ (Patrick, Stanbrook); Department of Medicine, University of Toronto (Stanbrook), Toronto, Ont.

Correspondence to: CMAJ editor, cmaj@cmajgroup.ca 